\title{
Bacteriophages to control Shiga toxin-producing E. coli - safety and regulatory challenges
}

\author{
Graça Pinto $^{\mathrm{a}}$ (D) Carina Almeida ${ }^{\mathrm{b}}$ (D) and Joana Azeredo ${ }^{\mathrm{a}}$ \\ ${ }^{a}$ CEB - Centre of Biological Engineering, LIBRO - Laboratório de Investigação em Biofilmes Rosário Oliveira, University of Minho, Braga, \\ Portugal; ' INIAV, IP-National Institute for Agrarian and Veterinary Research, Vairão, Portugal
}

\begin{abstract}
Shiga toxin-producing Escherichia coli (STEC) are usually found on food products due to contamination from the fecal origin, as their main environmental reservoir is considered to be the gut of ruminants. While this pathogen is far from the incidence of other well-known foodborne bacteria, the severity of STEC infections in humans has triggered global concerns as far as its incidence and control are concerned. Major control strategies for foodborne pathogens in foodrelated settings usually involve traditional sterilization/disinfection techniques. However, there is an increasing need for the development of further strategies to enhance the antimicrobial outcome, either on food-contact surfaces or directly in food matrices. Phages are considered to be a good alternative to control foodborne pathogens, with some phage-based products already cleared by the Food and Drug Administration (FDA) to be used in the food industry. In European countries, phage-based food decontaminants have already been used. Nevertheless, its broad use in the European Union is not yet possible due to the lack of specific guidelines for the approval of these products. Furthermore, some safety concerns remain to be addressed so that the regulatory requirements can be met. In this review, we present an overview of the main virulence factors of STEC and introduce phages as promising biocontrol agents for STEC control. We further present the regulatory constraints on the approval of phages for food applications and discuss safety concerns that are still impairing their use.
\end{abstract}

GRAPHICAL ABSTRACT

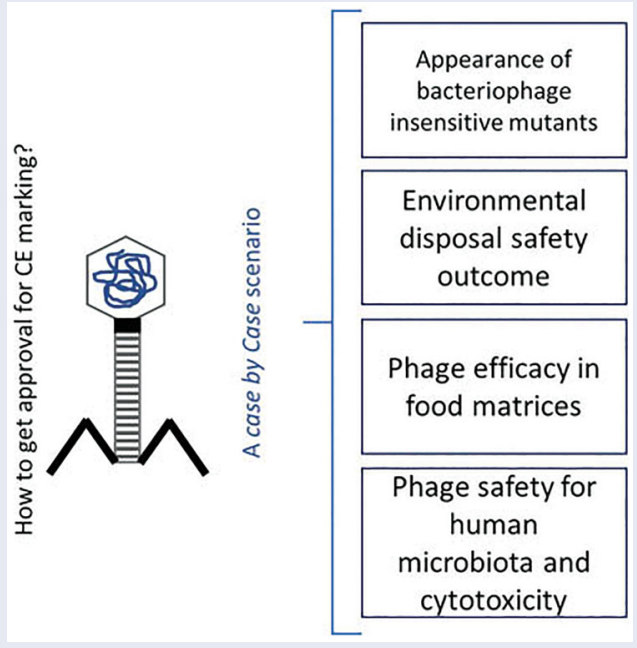

\section{ARTICLE HISTORY}

Received 14 August 2019

Revised 29 May 2020

Accepted 19 July 2020

\section{KEYWORDS}

STEC; bacteriophage; food biocontrol; safety;

regulatory; guidelines; gut

\section{Shiga toxin-producing Escherichia coli (STEC)}

Escherichia coli colonizes every mammal on the planet [1], and was first described in 1885 by the German physician Theodor Escherich [2]. Since then, E. coli has become one of the most well studied bacterial species [3]. Escherichia coli is a Gram-negative, non-sporulating facultative anaerobe that inhabits the intestines, being the most represented aerobe in the gastro-intestinal

CONTACT Joana Azeredo jazeredo@deb.uminho.pt @ CEB - Centre of Biological Engineering, LIBRO - Laboratório de Investigação em Biofilmes Rosário Oliveira, University of Minho, Braga 4710-057, Portugal

(1) Supplemental data for this article can be accessed here.

(C) 2020 Informa UK Limited, trading as Taylor \& Francis Group 
(GI) tract, outnumbered by anaerobic bacteria by $100 / 1$ to $10,000 / 1[2,4]$. Most $E$. coli strains belong to a heterogeneous group, typically nonpathogenic and beneficial, in the normal intestinal microbiome. However, there are some $E$. coli strains that are considered pathogenic to humans, such as the diarrheagenic group associated with $\mathrm{Gl}$ diseases [5-7]. The most important diarrheagenic $E$. coli pathogens are divided into 6 classes: enteropathogenic (EPEC), enteroinvasive (EIEC), enterotoxigenic (ETEC), enteroaggregative (EAEC), diffusely adherent (DAEC), and Shiga toxin-producing (STEC) (where enterohemorrhagic (EHEC) is a major subset) $[5,6]$. Recently, a new class of adherent invasive (AIEC), has also been described [8]. This division reflects the complexity and diversity of strains within this species, with some of them being allocated to different groups depending on the virulence gene being screened $[8,9]$. Among the pathogenic classes, STEC strains are the ones that are most commonly associated with severe foodborne outbreaks [10].

STEC strains are characterized by the presence of the Shiga toxin 1 and/or 2 genes (stx 1 and stx2), typically acquired through a lambdoid bacteriophage [8], and are responsible for a number of human diseases, such as mild to severe diarrhea. The subset EHEC is normally associated with more severe conditions such as hemorrhagic colitis ( $\mathrm{HC}$ ) and hemolytic uremic syndrome (HUS). The latter frequently leads to renal failure among young children, as well as renal complications [11-13]. EHEC possesses the genes responsible for causing attaching-effacing (A/E) lesions on intestinal epithelial cells (such as EPEC), encoded on the Locus of Enterocyte Effacement (LEE) pathogenicity island, and express high levels of Stx toxins [11]. Although several $\mathrm{OH}$ serotypes have been identified, the STEC 0157:H7 serotype is the most well-known among them, in addition to being the most studied one. The US Department of Agriculture (USDA) has considered this serogroup as being a food adulterant since 1994. The "Big 6" non-0157 STEC strains, O26, O45, 0103, 0111, 0121, and 0145, are usually found associated with severe disease in humans, and were also declared as adulterants [8]. In 2016, in "trends and sources of zoonoses, zoonotic agents and food-borne outbreaks," the European Food Safety Agency (EFSA) reported that in Europe the most prevalent serogroups following 0157 were 026, 0103, 091, 0145, 0146, and 0128 [14]. There are several schemes for STEC classification, and the simplest is the one that divides into E. coli 0157 and non-O157 STEC. This scheme is based on the prevalence of the 0157 serotype [15], but over the last years, other serotypes are increasing their prevalence.
The transmission of STEC occurs via the fecal-oral route, usually occurring by the intake of contaminated food or water, direct contact with animals, or personto-person transmission. The major reservoirs are ruminants, especially cattle [15]. The known infectious dose for STEC is very low (less than 100 microorganisms) [13], and these strains are able to form viable-but-nonculturable cells capable of producing Shiga toxin [8], which can make the detection and control of these pathogens even more difficult.

\section{Virulence factors of STEC}

As previously discussed, the presence of the genes encoding for Shiga-toxin (Stx) 1 and 2 is considered as the major virulence factor of STEC strains, and the latter is associated with more severe disease outcomes. Besides the type of a specific Stx and its potency, the amount of Stx toxin produced is another important factor to take into account when evaluating the virulence outcome [16]. Each type of Stx has variants: Stx 1 has 3 (a, c and d), and Stx2 has 7 variants (from a to g) [8]. STEC strains can either carry one gene for Stx 1 or Stx2, both genes, or a combination of Stx2 variants. Strains containing the variants of Stx2a and Stx2c are most commonly isolated from HUS cases [8,16-18]. The Shiga toxin is an $A B_{5}$, in other words, it is composed of a catalytic $A$ subunit, and a pentamer of $B$ subunits, responsible for the recognition and binding to receptors. Initially, in 1986, it was demonstrated by Jacewicz et al. that the Shiga toxin could bind to the glycosphingolipid globotriaosylceramide (Gb3) [19]. Nowadays, however, it is well known that toxin subtypes can bind to other receptors with different affinities. Stx1a prefers Gb3, but can also bind to globotetraosylceramide (Gb4), in turn, Stx2a binds preferentially to Gb3. Stx2e is the subtype with a wider range of receptors, preferring Gb4, but also binding to Gb3, pentahexosylceramides with Gb4-elongated core structures, and globopentaosylceramide (Gb5) [20]. After binding to the receptor, the Shiga toxin is internalized by the cell, and transported to the Golgi apparatus. Then, the A subunit that consists of 2 fragments connected by an internal disulfide bond, is cleaved by the enzyme furin, and the $A 1$ fragment is transported into the cytoplasm. A1, has an RNA N-glycosidase activity and inactivates the $60 \mathrm{~S}$ subunit, inhibiting protein synthesis $[20,21]$.

The Shiga toxin gene is acquired by $E$. coli strains through the insertion of a prophage, known as Shiga phage. Shiga phages are lambdoid phages capable of inserting themselves in specific sites into the chromosome of several $E$. coli serogroups $[16,17,22,23]$, and 
even other members of the Enterobacteriaceae family, such as Salmonella enteriditis serovars Cholerasuis, Typhi, and Typhimurium [24]. Stx phages, as lambdoid phages, prefer the lysogenic state, that is, they are stable until some stress factor triggers an S.O.S. response of the cell. Some examples of stress factors include DNA damaging agents, such as several antibiotics like mitomycin C, olaquindox [25,26], or ciprofloxacin [27], in addition to some external factors, such as UV irradiation and High Hydrostatic Pressure [17]. The S.O.S. response leads to the lytic cycle, resulting in phage replication and subsequent bacterial lysis. During this process, the Stx toxin is expressed and released [28]. Iversen et al. [29] studied some commensal E. coli that was lysogenized by a prophage from the highly virulent EHEC strain, O103:H25 (NIPH-11060424), which was responsible for the 2006 Norwegian outbreak. Most of the newly lysogenized $E$. coli produced more phages than the original strains, and a few even produced the phage without any induction agent. This result suggests that the stx gene can be easily transferred through transduction to commensal $E$. coli, which in turn will spread the toxin gene further, as it might have been the case during the 2006 outbreak [29].

Each Stx phage has only one stx gene, however, since there are several Stx phages in the environment with high genetic diversity, especially in the integrase gene, more than one Stx phage can integrate into the same bacterial chromosome at different insertion sites [16]. In the study of Steyert et al. [16], it is shown that what determines the insertion site is the phage integrase rather than the availability of the insertion sites. Furthermore, it is proven that integrases and stx genes have no phylogenetic correlation [16]. Stx phages are players on the horizontal gene transfer that drives the evolution of STEC strains. An example of this is the emergence of a new serogroup that encodes stx genes, the hybrid EAEC/STEC E. coli 0104:H4 which has recently acquired the stx2 gene [8,30]. Furthermore, some STEC strains have the ability to frequently lose and acquire Stx phages, such as STEC O26: $\mathrm{H} 11$, both in vitro and in vivo [25,31]. This also increases the diversity of prophages being exchanged among related $E$. coli in the environment.

The subset EHEC, or LEE-Positive STEC, is frequently characterized by the presence of the LEE pathogenicity island, which is a $35 \mathrm{~kb}$ chromosomal pathogenicity island $[15,16,32]$. A/E lesions occur by the attachment of the bacteria to the host cell, mediated through the destruction of the microvilli, and beneath the attachment site, there is a production of actin filaments, called actin pedestals, and other cytoskeletal proteins.
In the LEE pathogenicity island, an adhesion intimin is encoded, which is an outer membrane adhesin protein encoded by the eae gene, its translocated receptor Tir, a type III secretion system (T3SS), and several effectors $[15,32]$. However, not all STEC strains that cause HC and HUS are Lee- and eae-positive [13]. Some LEE-negative STEC have been known to cause severe diarrheal symptoms and HUS. While the Stx toxin is an important factor of virulence, it is not the sole factor responsible for the progression of HUS. This means that most LEEnegative STEC strains have an LEE-independent mechanism of adherence responsible for their virulence. Steyert et al. [16] studied 9 LEE-negative isolates (7V, 94C, B2F1, C165-02, DG131, EH250, MHI813, 031, S1191) and demonstrated that they do not present a common virulence factor for adhesion.

Several other virulence factors have already been identified, such as the long polar fimbrial gene cluster, and others in virulence plasmids, such as the p0113. This plasmid, as well as p0157, carries genes encoding enterohemolysin $(e h x \mathrm{~A})$ and serine protease autotransporter of Enterobacteriaceae (espP). Other virulence genes were exclusively found in LEE-negative strains, like the STEC autoagglutinating adhesion (saa) [16]. Information on virulence determinants has been arising very quickly, and there are already a large number of genes to take into account when evaluating the pathogenic potential of $E$. coli. Table 1 presents an overview of the virulence factors so far described, as well as their potential role in the infection mechanisms [8,32].

\section{Europe and STEC - what has been conducted so far}

Programs for the surveillance and prevention of 0157 and non-157 STEC are being implemented in Europe, the USA, and in other countries, and are considered of extreme importance for the efficiency on STEC control. In the European Union, all member countries are obligated to report any outbreak and annual reports are also published. In these reports, a thorough analysis of the epidemiological characteristics of infections is provided.

In 2015, 30 European Union/European Economic Area (EU/EEA) member countries reported STEC infections, accounting for 6151 confirmed cases. The rate was 1.5 cases per 100,000 population, keeping within the same values as those in the preceding three years. In 2011, there was a large outbreak due to EAEC/STEC 0104:H4 contamination on raw sprouted fenugreek seeds, which infected more than 3800 people located in Germany alone, in addition to more cases in 15 other 
Table 1. Some of the virulence factors described for STEC, and their role in pathogenesis.

\begin{tabular}{l} 
Virulence factor \\
\hline Shiga toxin \\
Locus of Enterocyte Effacement \\
(LEE) pathogenicity island (PAI)
\end{tabular}

(LEE) pathogenicity island (PAI)

Intimin

Cytolethal distending (CDT-V) toxin

EHEC hemolysin (EHEC-Hly)

Enterohemorrhagic E. coli

Autotransporters (Eha)

Serine Protease Autotransporters

STEC autotransporter mediating

Biofilm formation or Sab

Calcium-binding Antigen 43

Homologous or Cah

autotransporter

Adhesins eae

cdtA, cdtB, cdtC

ehxA or EHEC-hlyA

ehaA, ehaB, and ehaJ

espP

$s a b$

cah

eibG, efa-1/lifA/toxB

Ifp and elf

hсpA

subAB

Role in pathogenesis

Ref.

Stx toxin is composed by 2 subunits, $A$ and $B$. The $A$

subunit is a RNA-glycosidase that interacts with the

60S rRNA, inhibiting protein synthesis, causing

cell death.

LEE-PAI encodes several genes involved in the adhesion mechanism called attaching-and-effacing (A/E) lesion, such as type III secretion system (TTSS), an outer membrane adhesion (intimin), its translocated intimin receptor (TIR), and secreted proteins with signal transduction.

The eae gene is carried by the LEE-PAI, encoding an outer membrane adhesion protein, called Intimin. This protein interaction with the bacterial translocated intimin receptor (Tir) leads to the attachment of STEC cell to the host intestinal mucosa, resulting on the $A / E$ lesions.

CDT is a tripartite toxin composed of three peptides ( $C d t A, C d t B$ and $C d t C)$. It is believed that $C d t B$ is the catalytic domain with DNase I-like activity, that when in the nucleus of the host cell triggers the DNA damage response, impairing the cell cycle. $C d t A$ and $\mathrm{CdtC}$ are responsible for cell recognition and $\mathrm{CdtB}$ transportation into the nucleus.

EHEC-hlyA is part of an operon composed by four genes (EHEC-hlyC, EHEC-hlyA, EHEC-hlyB, EHEC-hlyD), encoded on the p0157 plasmid. EHEC-hlyA codes the structural protein of EHEC-Hly. The proteins coded by EHEC-hlyB and EHEC-hlyD are responsible for the transport of EHEC-Hly out of the bacterial cell, in its turn EHEC-hlyC product is responsible for EHEC-Hly pos-translational activation. EHEC-Hly is responsible for forming pores into the cell membrane, and is found as free, or in association with outer membrane vesicles (OMV). Both forms target the human intestinal epithelial and microvascular endothelial cells, but in different manners. When in the free form EHEC-Hly is responsible for lysing the cells, but when in association with OMV induced cell apoptosis.

Encoded in the LEE-PAI, belongs to the adhesin involved in diffuse adherence family, and is involved in attachment to biological and abiotic surfaces.

Encoded on the p0157 plasmid, it is important for biofilm formation, and for adherence to T84 intestinal epithelial cells.

Involved in the adherence to abiotic surfaces and epithelial cells. It is thought to be involved in the adherence to enterocytes of STEC strains that lack the ability to form A/E lesions.

Encoded in the LEE-PAI, this autotransporter is involved in bacterial autoaggregation, promoting bacteriumto-bacterium interactions.

Immunoglobulin-binding (Eib) $G$ is encoded by the gene eibG, and can bind to human $\lg D$ and $\lg A$. It can also participate in bacterial adhesion to host epithelial cells. Toxin Efa-1 is similar to LifA and ToxB, and they are thought to be associated with cell adherence, lymphostatin activity, or induction of secretion of type III effectors in the STEC strain.

Able to attach the extracellular matrix protein laminin, which contributes to colonization of the $\mathrm{Gl}$ tract.

Forms long bundled fibers, which recognize matrix proteins on epithelial cells. Involved in biofilm formation, twitching motility, and in vitro cell invasion.

Believed to be more toxic than Stx toxin, SubAB is internalized and trafficked to the endoplasmic reticulum (ER). The interaction of SubAB with a regulator of stress response in the ER, leads to cell death. Though to be involved with immune responses. 
countries. This implied an increment of about 1.8-fold, compared to the situation reported in 2010. However, the rate of prevalence stabilized between 2012 and 2015. In 2015, four outbreaks were reported, according to the European Center for Disease Prevention and Control (ECDC) "due to food contamination, being the sources 'mixed leaf lettuce and raw minced lamb,' 'chicken burgers and beef burgers', and 'various meat products'" [36].

In 2016, STEC was the fourth most reported zoonosis with 6378 confirmed cases, and the rate was 1.82 cases per 100,000 population, which represents an $8.3 \%$ increase when compared with the values from 2015 . The higher published rate may have arisen due to the stricter surveillance carried out after the outbreak, with the use of PCR for the detection of STEC in stool samples. The serogroup most commonly reported was 0157 with $38.6 \%$ of the cases, which represented a decrease in relative proportion in relation to non-0157 serogroups. The second most reported serotype was O26, representing the most frequent cause of HUS. Increased detection of non-0157 strains is related to the rising awareness of the danger of these strains, which led to an increase in the number of laboratories testing food products to $\mathrm{O} 157$ and, more recently, other serogroups [14]. STEC and other classes of E. coli-associated infections are usually linked either to fecal contamination of carcasses and/or to surfaces during the food processing steps or, as is the case with fresh vegetables and fruits, due to irrigation with contaminated water.

Surveillance reports also indicate the alarming prevalence of antibiotic-resistant STEC. In fact, a few reports have shown that a number of STEC strains isolated from food, animals, and humans, are resistant to some antimicrobials, such as lactams, carbapenem, and tetracycline $[37,38]$. Antibiotic-resistant bacteria that result from the misuse of antibiotics on farm animals can reach the population if present on food products of animal origin and is also due to other cross-contamination events [39]. Good manufacturing practices (GMPs) and Hazard Analysis Critical Control Point (HACCPs) have been implemented in food industries as a way to guarantee food safety. Despite their implementation and the fewer cases of foodborne contamination, foodborne outbreaks continue to occur [40]. The combination of these facts contributes to identifying the urgency of finding new strategies to control foodborne bacteria, thus keeping the environment and human health safety, in addition to reducing the harmful effects caused by the misuse of antibiotics.

The European Union allows the use of substances other than potable water for the decontamination of foodstuff of animal origin and food-contact surfaces, providing that the substances undergo a safety and efficiency evaluation before their authorization clearance by the competent entities (Regulation (EU) 853/ 2004). At the moment, only one substance has obtained this authorization - Latic Acid to be used on bovine meat (Retrieved from EFSA https://www.efsa.europa.eu/ en/applications/biologicalhazard/faq in May 2020). Not only chemical substances can be used, but biological agents can be considered as well. Bacteriophages are among the biological agents that have already been submitted for analysis.

\section{Bacteriophages - why?}

Bacteriophages (phages) are obligate bacterial viruses. The first evidence of the existence of phages occurred in 1896 and 1898, when strong antibacterial activity was observed in Vibrio cholera and Bacillus subtilis, respectively [41]. However, it was Frederick Twort, an English medical bacteriologist, when observing a similar phenomenon in Micrococcus in 1915, suggested that viruses were responsible for this activity [41-43]. In 1917, the French-Canadian microbiologist d'Herelle, observed an "invisible microbe" present in bacteria-free filtrates of stool samples from dysentery patients [44]. These "invisible microbes" were responsible for the lysis of liquid suspensions, and for the creation of clear zones in bacterial lawns. d'Herelle, explained, for the first time, that these viruses replicate at the expense of bacteria, leading to their death and subsequent lysis [41]. Phages outnumber bacteria tenfold, and it is estimated that the phage population is composed of about $10^{31}$ phage particles, they being the most abundant entities on Earth $[41,45]$. Considered as a very heterogeneous group, phages are classified not only by their nucleic acid composition (dsDNA, ssDNA, dsRNA, and ssRNA) but also by their morphologic structure. Most phages are tailed (about 96\%) and belong to the order Caudovirales. Until recently, Caudovirales' phages were further classified into one of three families, Podoviridae (short tail), Siphoviridae (long non-contractile tail), and Myoviridae (contractile tail) [46]. Nevertheless, due to the high genetic diversity, some phages of the family Myoviridae have been reclassified into one of two new families - Ackermannviridae and Herelleviridae [47].

Phages can be found wherever is their specific host since they need a viable bacteria cell to replicate and propagate [48]. The phage replication cycle starts with: adsorption, penetration, replication of nucleic acids, and the formation of virions. This will lead to lysis and subsequent release from the cell. Phages are usually 
specific for bacterial species, or even strain-specific. Notwithstanding this, there are some phages that are able to infect different species. The specificity is determined by the presence of receptors located on the surface of bacterial cells, such as LPS fragments or other surface proteins [49]. There are two types of phages, temperate or lytic, depending on the life cycle they enter upon infection. The infection of lytic phages always leads to the lysis of the host with the release of the progeny. As such, lytic phages are the chosen ones for antimicrobial applications. On the other hand, temperate phages enter the lysogenic cycle, which means that their genome will integrate and coexist on the host genome in a stable manner (known as prophage), replicating whenever the host cell also replicates. Temperate phages can enter the lytic cycle if an external factor (usually causing some stress into the cell), leads to the prophage induction (Figure 1). The switch from lysogenic to the lytic state has been a relevant matter of study in the past few years [28,50-52]. Some phages, like the lambdoid Stx phages, depend on the activation of the RecA-dependent bacterial S.O.S. that is usually damaged on the single-stranded DNA fragments. Prophage induction occurs after the RecA protein, an important recombinase from the DNA repair system, stimulates the cleavage of an S.O.S. regulon repressor (LexA protein) and a cl phage repressor, leading to the production of phage progeny (See explanation in Figure 1(A)) [53,54]. Stx phages take advantage of the S.O.S. response when infecting mammalian cells. For example, if in contact with $\mathrm{H}_{2} \mathrm{O}_{2}$ or superoxide released by the leukocytes and neutrophils, the S.O.S. response is activated, and thus the Stx toxin is produced and released, leading to the death of eukaryotic cells. Nevertheless, some studies demonstrate that spontaneous induction is an important feature of Stx phages which requires a smaller amount of RecA for the induction to occur [55].

In the context of food safety, lytic phages are interesting tools [48]. Phages are considered a natural agent,



Figure 1. The life cycles of a bacteriophage. The first step on phage replication cycles is attachment to the host cell by the recognition of receptors into the bacterial membrane (Adsorption). Then, phages inject their genome into the cell and enter the lytic cycle or the lysogenic cycle. Phages that enter the lytic cycle have their genome transcribed and translated into new phage particles that are then released from the cell by lysis. In the lysogenic cycle, the phage's genome inserts itself into the bacterial chromosome coexisting as a prophage, in a stable manner until some external (stress for the bacteria) factor causing prophage induction, leading to the lytic cycle. (A) RecA protein binds to single-strand DNA, resulting in the cleavage of LexA and cl phage repressor. LexA cleavage leads to the expression of S.O.S. genes. Furthermore, the expression of S.O.S genes can lead to the production of repressor proteins that will bind to the prophage repressor, resulting in its excision, and starting the lytic cycle. 
in contrast to other food chemical preservatives that are associated with severe health problems, such as cancer, asthma, and others [56]. Recently, there has been an increase in the popularity of green and nonchemical technology concerning the control of food contamination $[48,57]$. When compared to other biocides (including antibiotics), phages present several advantages. They are highly specific toward one species; so far there are no known side effects toward mammalian cells. They are present in all environments, including food products; and are known to be active against biofilm structures and they do not alter food organoleptic properties $[48,57]$. In the last few years, considerable research on the use of phages to control E. coli contamination in the context of food safety has been accomplished. Phages can be applied in the food chain, from pre-slaughtering (reviewed elsewhere [48]) to food products and food industry processing.

\section{Bacteriophages for controlling E. coli populations}

Numerous studies accomplished hitherto have already demonstrated the capability that phages possess to control enteric E. coli on food products. An overview of the studies performed over the last few years (from 2011 to present times) is provided in (Supplementary information Table 1). A good example of phage applications in food is offered by Tomat et al. [58,59]. In their study, they characterized 2 phages, DT1 and DT6, which have been isolated from the stool samples of patients with diarrhea. When tested on meat products, a significant reduction of viable cells of EPEC and STEC (around 1 log for single phage application and 2 log for cocktail) were observed, when compared to the controls without phages, at both temperatures tested $\left(5\right.$ and $\left.24^{\circ} \mathrm{C}\right)$. The best phage efficacy was obtained when phages were applied at concentrations ranging from $1.4 \times 10^{9}$ to $1.7 \times 10^{10} \mathrm{PFU} / \mathrm{mL}$, which corresponds to a Multiplicity of Infection (MOI) of $2.2 \times 10^{2}$ (for single phage applications) to $3.33 \times 10^{5}$ (cocktail application) and were shorter observed after phage application (3- and 6-h). The aforesaid authors also demonstrated that the phage did not lyse nonpathogenic strains, targeting only the pathogenic ones. A low emergence of Bacteriophage Insensitive Mutants (BIMs) was recorded. Furthermore, mutants isolated after inoculation with phage DT6, showed reversion unlike mutants resistant to phage DT1 which maintained their resistance after several rounds of subculture [58]. The same phages, DT1 and DT6, were used as biocontrol tools for STEC, EPEC, and as a nonpathogenic E. coli strain on milk fermentation. Both phages, either individually or in a cocktail, were able to control the growth of all E. coli strains without compromising the starter culture - the species Streptococcus thermophiles 10-C [59].

Similar, to what happens in meat or milk, in seafood the contamination by enteric bacteria due to inappropriate food-handling practices can also lead to foodborne diseases and to significant revenue losses. Le et al. [60] used phages to control both E. coli and Salmonella enterica subsp. enterica strains, as single and combined applications. The treatment resulted in a reduction of these bacteria in oysters [60].

Reports on the efficiency of a cocktail of three lytic phages specific for $E$. coli 0157:H7 (under the trademark EcoShield ${ }^{\mathrm{TM}}$ by the North American company Intralytix, Inc.) in lettuce are good examples of the antimicrobial effects of phages in freshly cut vegetables [61-65]. The phage cocktail solution has been applied in two different ways: by immersion or spraying the lettuce. Both forms of application led to a reduction of viable cells. The 2 min immersion in higher titer phage solutions resulted in the reduction of $E$. coli cells to undetectable levels at days 6 and 7. The spraying technique was very effective at immediately reducing E. coli O157:H7 populations on freshly cut lettuce; it is believed that the spraying technique disperses more phages on the lettuce surface. Furthermore, phage treatment can be used synergistically with a hypochlorite solution [61].

Apart from the food samples, some phages have also been tested in environmental samples associated with the food processing settings. In this regard, biofilms play an important role in the food industry. This ability of bacteria to attach to the surface of both food products, or to the facilities that constitute a reservoir for food contamination, which endangers human health [40]. Biofilms are a community of bacteria cells protected in an extracellular matrix [40] which can be composed of: polysaccharides, proteins, nucleic acids, and/ or lipids, with channels that allow for the distribution of key resources. The biofilm structure protects bacteria not only from external environmental damages but also from antimicrobial agents and the host immune system. Dalmasso et al. [66] isolated three new phages and characterized them in terms of their anti-biofilm potential. All three phages have been tested against biofilms for periods of 24 and $48 \mathrm{~h}$ individually and in a cocktail. The cocktail composed of the three phages, was the better option found for biofilm control since it prevented the formation of BIMs. In another study, Cui et al. [67] performed sequential treatment with Cold Nitrogen Plasma (CNP) and phages in order to control the formation of E. coli O157:H7 biofilms. This sequential treatment provided a reduction of 5.71 log CFU/ 
$\mathrm{cm}^{2}$, quite higher than the ones observed for CNP or the phages alone (about $2 \log \mathrm{CFU} / \mathrm{cm}^{2}$ ) [67]. In 2017, Sadekuzzaman et al. [68] reported the treatment of biofilms formed by strains ATCC 43889, NCCP 11090, and NCCP 14541 on different surfaces (stainless steel, rubber, and leaf) at two different temperatures (10 and $30^{\circ} \mathrm{C}$ ), using the lytic phage BPECO 19. After 2-h, phage BPECO 19 was able to reduce bacteria numbers of biofilms formed at both temperatures and on different surfaces, with lower efficacy on the leaf surface. Overall, the results suggest that the phage can control biofilms at different temperatures. However, the type of surface influences the biocontrol outcome [68]. The applicability of phages to control biofilms formed on surfaces of stainless steel used during vegetable harvesting was demonstrated by Patel et al. [69]. In this study, spinach harvester blades were inoculated with a spinach extract containing five $E$. coli $0157: \mathrm{H} 7$ strains for $48-\mathrm{h}$. A phage cocktail (8 log PFU/mL) was used to spray each side of the blade. After 2 -h, at room temperature $\left(22^{\circ} \mathrm{C}\right)$, the population of $E$. coli cells (initially of $4.87 \mathrm{CFU} / \mathrm{blade}$ ) was reduced to undetectable levels [69]. The study of Lee et al. [70] showed that a cocktail composed by phages BECP2 and BCEP6 was efficient at reducing $E$. coli O157:H7 biofilms formed on glass wool, microtiter plates, and stainless steel coupons [70]. Tomat et al. [71], on the other hand, chose glass coverslips and stainless steel as food processing materials as representatives to form biofilms. A cocktail composed by phages DT1 and DT6 was used to treat EPEC920 and 0157:H7 STEC464 biofilms, and another cocktail composed by DT5 and DT6 to treat non-0157 STEC ARG4827. As a control, the hard surfaces were treated with Hershey$\mathrm{Mg}$ broth, or not treated at all (dry control). Treatments were performed at 4 and $37^{\circ} \mathrm{C}$, for 1,3 , and 24-h periods. Biofilms formed on both materials were reduced at both temperatures. However, non-0157 STEC ARG4827 and 0157:H7 STEC464 were still detected at $4{ }^{\circ} \mathrm{C}$ in glass coverslips, and the latter was only reduced in 1.5 $\log \mathrm{CFU} / \mathrm{mL}$ at $37^{\circ} \mathrm{C}$. Reduction on stainless coupons was more efficient for all strains tested, nevertheless, EPEC920 and 0157:H7 STEC464 were detectable after $24 \mathrm{~h} \mathrm{[71].}$

These studies demonstrate the potential of phages to be used in food products for the biocontrol of $E$. coli O157:H7. Phages are a promising tool to control foodborne pathogens, not only as food additives but also in the environmental biocontrol throughout the different steps of the food production chain. Phages can be used in different ways namely: during the prevention and control of colonization on livestock, in the reduction of the number of contaminations on food products, such as carcasses, or even ready-to-eat products, and lastly, they can be used to extended shelf life. Despite their great potential, the use of phage-based products is limited by some factors such as the type of food matrix (for instance, some food samples have low water activity or high salt concentrations, which can impair phage efficacy) and the food processes (physical and chemical treatments during food processing can inactivate phages) [72]. Moreover, the introduction of phages in the food chain will eventually end up in the ingestion of phages and in their consequent interaction with the gut microbiome. This renders phage biocontrol some concerns, especially due to the fact that dysbiosis phenomena in the gut microbiome have recently been associated with some diseases [73-75]. In this regard, some studies have already demonstrated that phages targeting $E$. coli in the gut, when administered orally, can reduce this bacterium without damaging the microbiome composition, especially the number of commensal E. coli [76-78]. However, De Sordi et al. [79] published a study where a host range increase in the gut was observed in vitro and in vivo. This means that the phage has gained the ability to infect new hosts, and sometimes this happens to the detriment of infecting the original host. In the gut, the preferential host can be in a low number or even absent, which can lead to greater pressure on the phage [79]. Thus, when phages are administered to humans, even if in a small number through the ingestion of food products, a safety study should be undertaken. The interaction of phages with the gut microbiome will be addressed in more detail below.

As can be seen in "Supplementary information," the biocontrol of STEC by phages has mainly focused on the treatment of 0157 strains. Nevertheless, lately, with new developments of detection methodologies, other serotypes have been recognized as relevant, hence the prevalence of 0157 has been reduced [14]. Nonetheless, E. coli 0157 remains the most relevant pathogenic E. coli. In 2006, the US Food and Drug Administration (FDA) approved the phage cocktail Ecoshield $^{\mathrm{TM}}$ from Intralytix, Inc (Baltimore, MD) for the control of this foodborne pathogen in "red meat parts and trim intended to be ground" [80]. However, the approval of this product is yet to be achieved in the European Union.

\section{Phage-based products regulations}

As mentioned in the previous section, the phage-based product EcoShield $^{\mathrm{TM}}$ for control of E. coli O157:H7 was designed to be used in "red meat parts and the trim is 


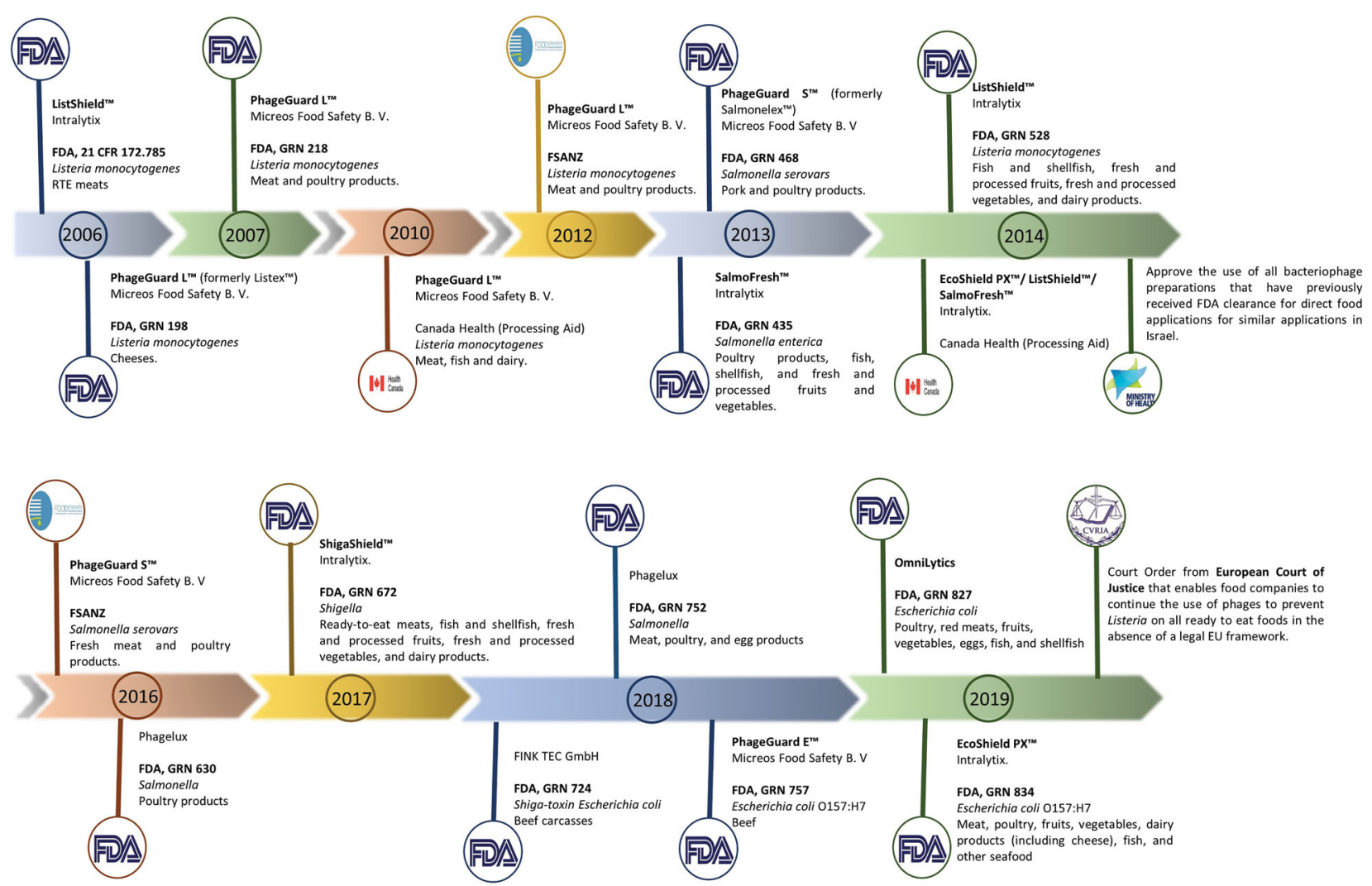

Figure 2. A worldwide timeline of the phage-based products which have already been approved. Description of products includes the manufacturing company, the target bacteria and the food matrix where the product is intended to be applied. The timeline was constructed using information from the FDA, FSANZ, and the companies' news websites.

intended to be ground" (Retrieved from Intralytix webpage http://www.intralytix.com/index.php?page=prod\& id=2, August 2019). However, a different product, Secure Shield E1, from the FINK TEC GmbH company (Germany) is intended to be used on the "surfaces of beef carcasses." Both products have been approved by the FDA. Recently, PhageGuard E. from Micreos (Netherlands), a phage mixture from OmniLytics (Sandy, UT), and EcoShield $\mathrm{PX}^{\mathrm{TM}}$ from Intralytix obtained approval to control STEC contamination on several food products. (Retrieved from GRAS Notices webpage https://www.fda.gov/food/generally-recognized-safegras/gras-notice-inventory, February 2020). FDA approved the phage products discussed above as Generally Recognized as Safe (GRAS) to be used as food additives. The Federal Food, Drug, and Cosmetic Act (FD\&C Act), as well as the regulations in Title 21 of the Code of Federal Regulations (21 CFR) are the base for the aforesaid classification, GRAS. For new substances intended to be used in human food, such as food additives, a requirement in accordance with the procedures in 21 CFR part 170, subpart E, should be submitted to the FDA [81]. This has been the preferred procedure for approving phages in the USA. Other countries have also approved the use of phages for food safety purposes (Figure 2). In 2014, in the "Guidelines: use of bacteriophages (bacteria-killing viruses) in food," the National Food Service from the Israeli Ministry of Health, approved all phages that had already been cleared by the FDA to be used for similar applications [82]. In Canada, the phage-based products PhageGuard $\mathrm{L}^{\mathrm{TM}}$ (formerly Listex ${ }^{\mathrm{TM}}$ ), ListShield ${ }^{\mathrm{TM}}$, SalmoFresh ${ }^{\mathrm{TM}}$, and EcoShield $^{\mathrm{TM}}$, and others, were approved as a processing food aid $[82,83]$. A request for the acceptance of a new substance should be submitted to the Bureau of Chemical Safety, within the Health Canada's Food Directorate, which will assess the submission and express an opinion. Health Canada keeps a list of Antimicrobial Food Processing Aid uses on Red Meat and Poultry Meat for which "No Objection" was emitted (Retrieved from https://www.canada.ca/en/health-canada/services/food-nutrition/food-safety/food-additives/ processing-aids.html\#a1 in February 2020). In Australia and New Zealand, the Food Standards Australia New Zealand approved the use of phage-based preparations to control Listeria monocytogenes and Salmonella as Processing Aids for certain RTE products [84].

In Europe, the scenario is quite different. Despite the fact that the approval of phage-based products has already been pursued $[85,86]$ and, as of yet, there is no 
product with the CE marking. As stated in Article 3.2 of Regulation (EU) 853/2004, which stipulates the hygiene rules for food of animal origin, "Food business operators shall not use any substance other than potable water $(\ldots)$ to remove surface contamination from products of animal origin, unless use of the substance has been approved in accordance with the procedure referred in article 12 (2) (...)."

The Council, which is the legal entity that approves the new laws [87] jointly with the European Parliament, should follow the referred procedure established in Articles 5 and 6 of Decision 1999/468/EC, the Regulatory and Safeguard procedures, respectively [88]. For the decision of both procedures, a specialized committee should deliver its opinion on the subject matter, in the predetermined time, so a qualified decision can be made [88]. For phage applications, the Council requested that the EFSA issues their scientific opinion. It should be noted that EFSA only provides the scientific opinion on the products, and is not liable for the final decision on the approval of such decontamination products. The European Commission and the Member States take responsibility for the final approval (Retrieved from https://www.efsa.europa.eu/en/applications/biologicalhazard/regulationsandguidance in May 2020). Thus, in 2009, at the request of the European Commission, the EFSA published a scientific opinion on "The use and mode of action of bacteriophages in food production." The document focuses on the mode of action of phages when applied on different food surfaces of animal origin, explaining how phages infect bacteria, and also how they can be used to control the growth of pathogens. The EFSA Scientific Committee could neither conclude if phages were able to control the recontamination of food with bacterial pathogens, nor the capability of phages to control the low number of bacteria naturally present on food products. Moreover, in the report described, the same scientific committee provided some recommendations for the safe use of phages, such as the use of strictly virulent phages to be used at high $\mathrm{MOI}$. The higher proportion of phages in relation to the target bacteria is believed to lead to higher reductions of the latter and diminish the emergence of BIMs, whose presence should be avoided if possible. Moreover, the use of phages that are active against stationary cells (i.e. cells with a lower metabolic activity) is suggested. For the EFSA scientific committee, each new phage that seeks approval to be used as a decontamination substance should submit a Guidance Document (a case by case analysis), given the diversity of phage outcomes [89]. Due to their diversity, phages were excluded from the list of Qualified
Presumption of Safety (QPS) microorganisms to be used on food and feed by EFSA in 2009. Up to now this exclusion still applies [90].

Despite the regulatory challenges, the product Listex $^{\mathrm{TM}}$ P100 has sought approval for its use as a decontamination substance to control Listeria monocytogenes on food, raw fish [85], and Ready-to-eat (RTE) food products [86]. Nevertheless, many food industries are already using this phage product to control Listeria in many food products. In October 2019, The European Court of Justice issued a Court Order that enables food companies to continue using phages to prevent Listeria on all ready-to-eat foods in the absence of a legal EU framework.

Clear and proper legislation for phage-based products does not yet exist on account of the great diversity of phages [91]. The EFSA considers that any phagebased product should be seen as unique and a complete study of its efficacy and safety will be required for approval to be obtained [92]. Accordingly, scientists and product development companies should direct their investigation to answer the concerns (reviewed below) of efficacy and safety that still concerns regulatory entities. This would speed up the preparation of safety and efficacy assessment reports, required in the regulatory process.

\section{Safety of phage-based products for STEC biocontrol}

The approval of phage-based products to be used as biocontrol agents in the EU will be dependent on exhaustive safety analysis. One of the major concerns raised by the EFSA is the selection of bacteriophage insensitive mutants (BIM) following a phage application. In fact, several studies of phage/host interaction show both a population regrowth shortly after phage application, and also part of this population being formed by BIMs $[58,66,93]$. Therefore, the selection for BIM is a setback for all phages' applications, including STEC biocontrol. Nonetheless, as overviewed by Moye et al. [94], the use of a phage cocktail could overcome this problem. A more complex cocktail (composed of phages targeting different receptors) seems to be a better option since multiple mutations will be required for the bacteria to gain resistance toward all phages within the cocktail [94]. An advantage of phage biocontrol in relation to other antimicrobials is the phages' narrow lytic spectrum, limiting the number of bacteria cells that will suffer selection pressure [91].

Another factor to take into account when considering phage biocontrol for STEC strains is that the major 
virulence factor is the production of Shiga toxins, which are encoded on the genome of prophages within the host genome. The expression of this toxin is usually induced by an external factor that triggers an S.O.S. response (as revised above). Several factors that may trigger toxins' expression have already been studied elsewhere $[26,27,95-98]$ and they include antibiotics, among others. It can still be further demonstrated that phage application is completely safe in this regard, for example, it is not known if lytic phages could also promote Shiga toxin release while killing the bacteria. This needs to be ascertained for any phage which is aimed to be used in STEC biocontrol. Nevertheless, it is most likely that phages will not affect Shiga toxin release, since there is no evidence that their interaction with the hosts would trigger the S.O.S. response.

Regarding the release of phages into the environment, STEC strains are commonly found in sewage and animal wastewaters $[99,100]$. Therefore, the risk of using lytic phages should be well assessed. Liao et al. [99] observed a correlation between the presence of STECspecific phages infecting several serogroups, and lower isolation of STEC strains in pre-harvest produce environments. It is worth mentioning that in this study the phages were isolated, especially in areas of human impact [99]. The phages found seem to be able to control the levels of bacteria load, and hence are an important component of the ecosystem. In the context of biocontrol and safety using a phage cocktail toward STEC, it is important to assess the real impact of such an application on the environment where phages will inevitably be discharged. The use of phages for the biocontrol of STEC is of great interest since the E. coli species is a very heterogeneous group, classified in different serogroups which are characterized by having different O-antigens [101]. An effort should be made to select phages that recognize strains of specific virulent serogroups, ensuring limited lytic activity toward other E. coli considered commensal in a certain ecosystem.

Additionally, several studies noted that some dietary alterations, antibiotics or even the ingestion of phages can alter the gut microbiota [102-106]. As E. coli is an important commensal of human microbiota [1], any possible disturbance can lead to severe outcomes (See Figure 3). When a phage-based product that has the potential risk of disturbing the normal $E$. coli population it is intended to be used in food (and, thus, is ingested), this risk should be further analyzed.
(A)

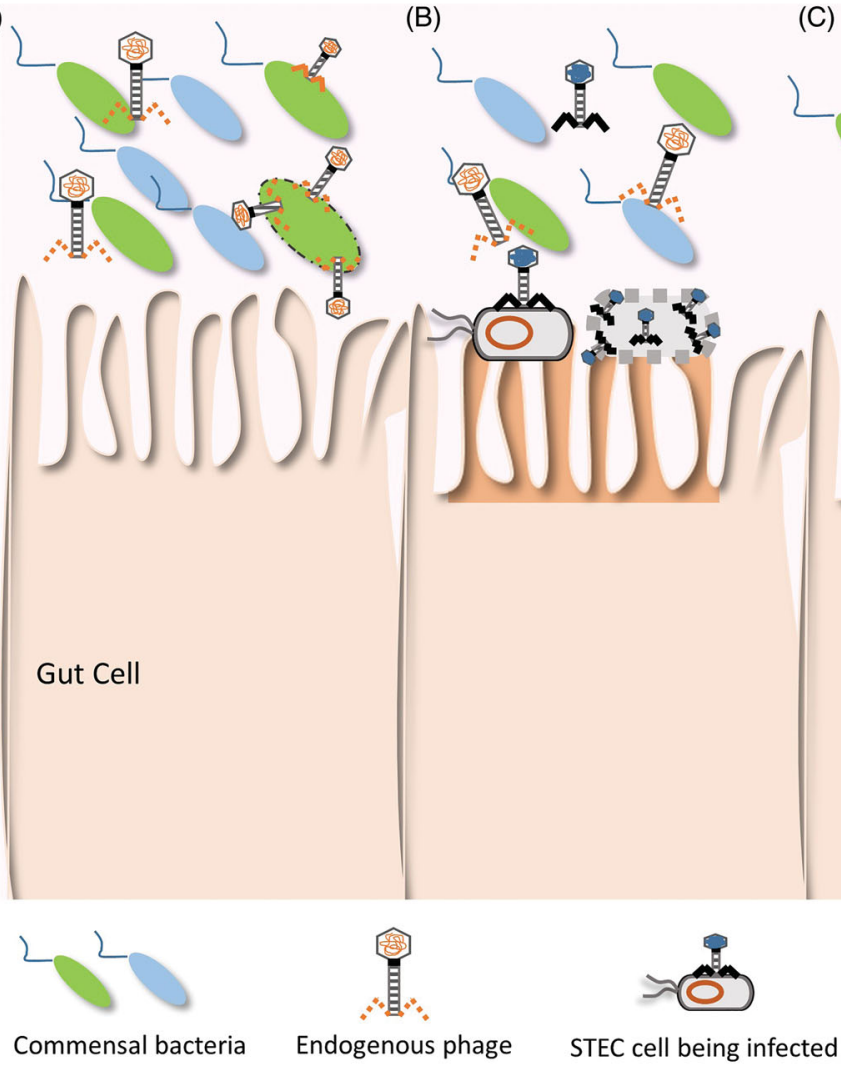

(C)

)

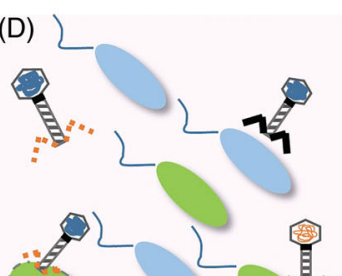

ississ

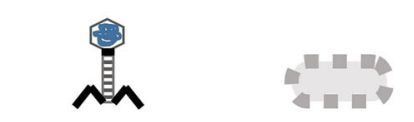

Exogenous phage

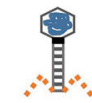

Mutant phage

Figure 3. Possible interaction of phages with the gut microbiome. In the healthy gut microbiome, bacteria and phages are naturally present (A); when an exogenous phage is administered to control an infection, it will target the susceptible host, whether they are the intended target-host (B) or a different host on the gut microbiome, leading to a dysbiosis (C). Exogenous phage can adapt to infect commensal bacteria (D). 


\section{How is the GUT microbiome affected by phages?}

Some studies report on the use of phages to control food contamination by targeting the pathogen on living animals prior to their slaughter or by applying them as disinfectants on food processing steps (revised elsewhere [107-109]). The inclusion of phages on the food chain will result in their presence on the consumers' table and their gut. While the direct impact of phages on human health has been superseded by some of the products being commercialized (and also by the long tradition of phage-based therapeutics in Western Europe) that have proved them as safe, the impact on the gut microbiome can be significant. This is even more relevant for $E$. coli that has been regarded as one of the most important species in the commensal gut [1]. In 2004, Bruttin et al. have already demonstrated that phage T4 (specific for E. coli) could survive the Gl tract which appears on the feces of human volunteers. However, at that time the composition of the gut microbiome was not evaluated. The phage used has a very narrow lytic spectrum, and it is very likely that no encounter with a suitable host will occur during the gut passage. This was in fact verified since no replication of the phage was observed [110].

Nowadays, there is a consensus regarding the fact that the gut microbiome (comprising bacteria, fungi, archaea, viruses, and protozoans) is of the utmost importance for human health. The dysbiosis of the gut microbiome can lead to severe diseases, and dietary, antibiotics, and other stress factors can be responsible for it [111]. In the gut microbiome, the most predominant viruses are phages. Recently, several metagenomics undertaken studies have elucidated the presence of phages, the temperate phages being the most common ones. Nevertheless, only a few studies have tried to answer the important questions: how do phages influence the microbiome, and what is the relationship between bacteria, phages, and the subjects' health conditions? [79] Two trials aiming to assess the safety of the phage in children were performed in Bangladesh by Sarker et al. in 2016 and 2017. Clinical trials were performed either in diarrheal children, or in both healthy and diarrheal children, demonstrating that the use of phage cocktails (containing T4 or T7-like viruses) are safe, and do not alter the composition of the gut microbiome [76,112]. It should be noted that the gut microbiome variability of the population in the study was independent of phage treatment $[76,112]$. In any case, in these studies, the cocktail used was not customized for the pathogens that lead to diarrhea, which can mean that most probably there was a lack of replication of phages in the gut. The phage amount recovered in the feces was never superior to the one given orally. Another possible explanation for the incapacity of phages to replicate in the gut consists of the low amounts of the pathogen which is responsible for diarrhea. The fact that phages did not replicate also explains the lack of improvement of diarrheal symptoms [112]. Nonetheless, the fact is that this study mimics quite well what happens with phages applied in food samples. Phages are subsequently ingested by healthy humans who - at least in theory - do not have the target pathogen in their gut.

Recently, Gindin et al. [113] accomplished an evaluation of the safety and tolerability of probiotic-containing phages, such as PreforPro (composed of 4 lytic phages targeting $E$. coli - K12, 16 enterotoxigenic strains and 2 enterohemorrhagic strains). In the abovementioned study, each participant received random phage treatment or a placebo for 28 days, followed by a washout period ( 14 days) before starting the opposite treatment for an additional 28 days. The authors concluded that the use of the probiotic formulation was safe and tolerated for human consumption, and also that it can be used by a healthy individual that shows mild to moderate symptoms of gastrointestinal distress [113]. Nevertheless, in this study, the composition of the gut microbiome was not assessed and consequently, it is not possible to affirm that the PreforPro is completely safe and able to control the symptoms of diarrhea.

The number of clinical trials that focus on studying the effect of phages on the gut environment is still quite scarce [112], and most studies are performed in simulated gut conditions or in animal models $[78,79,114]$. The observations made by Maura et al. [115] suggest that, as was to be expected, phages are able to replicate only when in the presence of the host in the mice gut. The authors used 3 specific phages for the strain O104:H4 EAEC 55989Str and observed that after only one application administered by oral gavage could replicate for a period of 2 weeks; however, the colonization levels of bacterium 55989Str on the mice feces would not be compromised. When, in the absence of a suitable host, the phages were not detected after day 9 of the application [115]. A similar study was undertaken by Cieplak et al. [78]: phage cocktail Ec17B153DK1, composed of 3 phages (ECML363, ECML-122, and ECML-359), with lytic activity against $E$. coli DSM 1058, was tested in a small intestine simulated model. A consortium of microorganisms comprising 7 bacterial species was used to simulate a normal and healthy microbiome. The phage cocktail, 
unlike the antibiotic ciprofloxacin, was able to reduce the target bacterium without compromising the commensal bacteria. It should be noted that, in the simulated model of the small intestine, only the target $E$. coli was used together with the other 7 species, however, phages were able to lyse other $E$. coli strains when tested in vitro. This suggests that phages used in this study could potentially lyse further $E$. coli strains in the gut [78]. In fact, the ability of phages to adapt to new hosts was demonstrated by De Sordi et al. [79], suggesting that bacterial diversity encountered by phages in the intestinal microbiota promotes genome diversification of phages [79] (Figure 3). So, despite the high specificity of phages, it is very likely that they might cause alteration in the gut microbiome by targeting commensal E. coli strains that display compatible receptors or, even as demonstrated by De Sordi et al. [79], by phages adaptation to new susceptible hosts. It is not yet clear if a potential interference with the gut microbiome could cause an imbalance, questioning the safety of phage application. These concerns need to be addressed by further, more in-depth microbiome studies, before phage therapy, can be adopted as a routine tool in the control of foodborne pathogens. In that sense, considering the relevance/prevalence of $E$. coli in the gut and its close phylogenetic relationship with several foodborne pathogens, this bacterium constitutes the ideal case study for future works in that field.

\section{Concluding remarks}

In an era of constant innovation and a search for new and more natural forms to control pathogens in food [94], phages have now acquired a renewed interest. The approval of phage-based products for the control of STEC strains is a reality in some countries, such as the USA, with some phage cocktail being considered GRAS by the FDA [116]. Still, in the European Union, there is concern regarding the use of these products due to the lack of safety and long-term studies on the effects of the release of phages into the environment. Nevertheless, these concerns might be addressed when proper guidelines and legislation are established for phage or phage-derived products. This will also increase the companies' willingness for investing in such products. Hitherto, studies have proved E. coli specific phages to be efficient tools for the biocontrol of STEC in food products, and some have even shown to be safe in humans. Nonetheless, recent developments on how human/animal microbiomes affect health conditions, adds an extra layer of complexity to phage application. The introduction of foreign phages for the control of an important inhabitant of the gut environment should be thoroughly analyzed to ascertain the possible outcomes on human health. When both this legislation and safety concerns are set aside we might face a new era of antimicrobials with an application at different value chains, starting with farm-level interventions, up to food decontamination, and human treatment.

\section{Disclosure statement}

No potential conflict of interest was reported by the author(s).

\section{Funding}

The authors thank the Portuguese Foundation for Science and Technology (FCT) through the strategic funding of UID/ $\mathrm{BIO} / 04469 / 2019$ unit, and the project PhageSTEC [PTDC/CVTCVT/29628/2017], under the scope of COMPETE 2020 [POCI01-0145-FEDER-029628]. The author GP acknowledges the FCT grant [SFRH/BD/117365/2016].

\section{ORCID}

Graça Pinto (D) http://orcid.org/0000-0002-9348-7553

Carina Almeida (D) http://orcid.org/0000-0002-0175-1119

Joana Azeredo (ID http://orcid.org/0000-0002-5180-7133

\section{References}

[1] Conway T, Cohen PS. Commensal and pathogenic Escherichia coli metabolism in the gut. Microbiol Spectr. 2015;3:343-362.

[2] Chaudhuri RR, Henderson IR. The evolution of the Escherichia coli phylogeny. Infect Genet Evol. 2012; 12(2):214-226.

[3] Clements A, Young JC, Constantinou N, et al. Infection strategies of enteric pathogenic Escherichia coli. Gut Microbes. 2012;3(2):71-87.

[4] Tenaillon O, Skurnik D, Picard B, et al. The population genetics of commensal Escherichia coli. Nat Rev Microbiol. 2010;8(3):207-217.

[5] Almeida C, Sousa JM, Rocha R, et al. Detection of Escherichia coli $\mathrm{O} 157$ by peptide nucleic acid fluorescence in situ hybridization (PNA-FISH) and comparison to a standard culture method. Appl Environ Microbiol. 2013;79(20):6293-6300.

[6] Robinson AL, Mckillip JL. Biology of Escherichia coli 0157:H7 in human health and food safety with emphasis on sublethal injury and detection. Curr Res Technol Educ Top Appl Microbiol Microb Biotechnol. 2010;2:1096-1105.

[7] Asea A, Kaur P, Chakraborti A. Enteroaggregative Escherichia coli: an emerging enteric food borne pathogen. Interdiscip Perspect Infect Dis. 2010;2010: 254159 
[8] Croxen MA, Law RJ, Scholz R, et al. Recent advances in understanding enteric pathogenic Escherichia coli. Clin Microbiol Rev. 2013;26(4):822-880.

[9] Robins-Browne RM, Holt KE, Ingle DJ, et al. Are Escherichia coli pathotypes still relevant in the era of whole-genome sequencing? Front Cell Infect Microbiol. 2016;6:141-149.

[10] Werber D, Krause G, Frank C, et al. Outbreaks of virulent diarrheagenic Escherichia coli - are we in control? BMC Med. 2012;10(1):11.

[11] Ranjbar R, Masoudimanesh M, Dehkordi FS, et al. Shiga (Vero)-toxin producing Escherichia coli isolated from the hospital foods virulence factors, oserogroups and antimicrobial resistance properties. Antimicrob Resist Infect Control. 2017;6:1-11.

[12] Kerangart S, Douëllou T, Delannoy $S$, et al. Variable tellurite resistance profiles of clinically-relevant Shiga toxin-producing Escherichia coli (STEC) influence their recovery from foodstuffs. Food Microbiol. 2016;59: 32-42.

[13] Newell DG, La Ragione RM. Enterohaemorrhagic and other Shiga toxin-producing Escherichia coli (STEC): where are we now regarding diagnostics and control strategies? Transbound Emerg Dis. 2018;65(1):49-71.

[14] European Food Safety Authority, European Centre for Disease Prevention and Control (ECDC). The European Union summary report on trends and sources of zoonoses, zoonotic agents and food-borne outbreaks in 2015. EFSA J. 2015;13(12):4329.

[15] Karmali MA, Gannon V, Sargeant JM. Verocytotoxinproducing Escherichia coli (VTEC). Vet Microbiol. 2010;140(3-4):360-370.

[16] Steyert SR, Sahl JW, Fraser CM, et al. Comparative genomics and stx phage characterization of LEEnegative Shiga toxin-producing Escherichia coli. Cell Infect Microbiol. 2012;2:1-18.

[17] Krüger A, Lucchesi PMA. Shiga toxins and stx phages: highly diverse entities. Microbiology. 2015;161(3): 451-462.

[18] Ercoli L, Farneti S, Zicavo A, et al. Prevalence and characteristics of verotoxigenic Escherichia coli strains isolated from pigs and pork products in Umbria and Marche regions of Italy. Int J Food Microbiol. 2016; 232:7-14.

[19] Jacewicz $M$, Clausen $H$, Nudelman $E$, et al. Pathogenesis of shigella diarrhea. XI. Isolation of a shigella toxin-binding glycolipid from rabbit jejunum and HeLa cells and its identification as globotriaosylceramide. J Exp Med. 1986;163(6):1391-1404.

[20] Lee M-S, Tesh V. Roles of Shiga toxins in immunopathology. Toxins. 2019;11:212.

[21] Robinson CM, Sinclair JF, Smith MJ, et al. Shiga toxin of enterohemorrhagic Escherichia coli type 0157:H7 promotes intestinal colonization. Proc Natl Acad Sci USA. 2006;103(25):9667-9672.

[22] Allué-Guardia A, Martínez-Castillo A, Muniesa $M$. Persistence of infectious shiga toxin-encoding bacteriophages after disinfection treatments. Appl Environ Microbiol. 2014;80(7):2142-2149.

[23] Martí-Nez-Castillo A, Muniesa M. Implications of free Shiga toxin-converting bacteriophages occurring outside bacteria for the evolution and the detection of
Shiga toxin-producing Escherichia coli. Front Cell Infect Microbiol. 2014;4:46-48.

[24] Rooks DJ, Yan Y, McDonald JE, et al. Development and validation of a qPCR-based method for quantifying Shiga toxin-encoding and other lambdoid bacteriophages. Environ Microbiol. 2010;12(5):1194-1204.

[25] Bonanno L, Petit MA, Loukiadis $E$, et al. Heterogeneity in induction level, infection ability, and morphology of Shiga toxin-encoding phages (Stx phages) from dairy and human Shiga toxin-producing Escherichia coli O26:H11 isolates. Appl Environ Microbiol. 2016;82(7):2177-2186.

[26] Kohler B, Karch H, Schmidt H. Antibacterials that are used as growth promoters in animal husbandty can affect the bacteriophages and Shiga toxins 2 from Escherichia coli strains. Microbiology. 2000;146(5): 1085-1090.

[27] Zhang X, McDaniel AD, Wolf LE, et al. Quinolone antibiotics induce Shiga toxin-encoding bacteriophages, toxin production, and death in mice. J Infect Dis. 2000;181(2):664-670.

[28] Feiner R, Argov T, Rabinovich L, et al. A new perspective on lysogeny: prophages as active regulatory switches of bacteria. Nat Rev Microbiol. 2015;13(10): 641-650.

[29] Iversen $H$, L'Abée-Lund TM, Aspholm $M$, et al. Commensal E. coli Stx2 lysogens produce high levels of phages after spontaneous prophage induction. Front Cell Infect Microbiol. 2015;5:5-10.

[30] Mitsunaka S, Sudo N, Sekine Y. Lysogenisation of Shiga toxin-encoding bacteriophage represses cell motility. J Gen Appl Microbiol. 2018;64(1):34-41.

[31] Bonanno L, Loukiadis E, Mariani-Kurkdjian P, et al. Diversity of Shiga toxin-producing Escherichia coli (STEC) O26:H11 strains examined via stx subtypes and insertion sites of Stx and EspK bacteriophages. Appl Environ Microbiol. 2015;81(11):3712-3721.

[32] Jores J, Rumer L, Wieler LH. Impact of the locus of enterocyte effacement pathogenicity island on the evolution of pathogenic Escherichia coli. Int J Med Microbiol. 2004;294(2-3):103-113.

[33] Farfan MJ, Torres AG. Molecular mechanisms that mediate colonization of shiga toxin-producing Escherichia coli strains. Infect Immun. 2012;80(3): 903-913.

[34] Bielaszewska M, Sinha B, Kuczius T, et al. Cytolethal distending toxin from Shiga toxin-producing Escherichia coli 0157 causes irreversible G2/M arrest, inhibition of proliferation, and death of human endothelial cells. Infect Immun. 2005;73(1):552-562.

[35] Bielaszewska $M$, Aldick $T$, Bauwens $A$, et al. Hemolysin of enterohemorrhagic Escherichia coli: structure, transport, biological activity and putative role in virulence. Int J Med Microbiol. 2014;304(5-6): 521-529.

[36] European Centre for Disease Prevention and Control. Shigatoxin/verocytotoxin-producing Escherichia coli (STEC/VTEC) infection. Solna (Sweden): ECDC; 2020. (Annual Epidemiological Report for 2018).

[37] Colello R, Etcheverría Al, Di Conza JA, et al. Antibiotic resistance and integrons in Shiga toxin- 
producing Escherichia coli (STEC). Braz J Microbiol. 2015;46(1):1-5.

[38] Amézquita-López BA, Quiñones B, Soto-Beltrán $M$, et al. Antimicrobial resistance profiles of Shiga toxinproducing Escherichia coli 0157 and Non-O157 recovered from domestic farm animals in rural communities in Northwestern Mexico. Antimicrob Resist Infect Control. 2016;5:1-6.

[39] Van Boeckel TP, Brower C, Gilbert M, et al. Global trends in antimicrobial use in food animals. Proc Natl Acad Sci USA. 2015;112(18):5649-5654.

[40] Gutiérrez D, Rodríguez-Rubio L, Martínez B, et al. Bacteriophages as weapons against bacterial biofilms in the food industry. Front Microbiol. 2016;7: 815-825.

[41] Melo LDR, Oliveira H, Santos SB, et al. Phages against infectious diseases. In: Paterson $\mathrm{R}$, Lima $\mathrm{N}$, editors. Bioprospecting. Braga (Portugal): Springer International Publishing; 2017. p. 269-294.

[42] Fernández L, Rodríguez A, García P. Phage or foe: an insight into the impact of viral predation on microbial communities. ISME J. 2018;12(5):1171-1179.

[43] Clokie MRJ, Millard AD, Letarov AV, et al. Phages in nature. Bacteriophage. 2011;1(1):31-45.

[44] d'Herelle F. Sur un microbe invisible antagonistedes bacilles dysenteriques. Les Comptes Rendus Del'Académie Des Sci. 1917;165:373-375.

[45] Grose JH, Casjens SR. Understanding the enormous diversity of bacteriophages: the tailed phages that infect the bacterial family Enterobacteriaceae. Virology. 2014;468-470:421-443.

[46] Ackermann H. Phage classification and characterization. Methods Mol Bio. 2009;501:127-140.

[47] Barylski J, Enault F, Dutilh BE, et al. Analysis of spounaviruses as a case study for the overdue reclassification of tailed phages. Syst Biol. 2020;69(1):110-123.

[48] O'Sullivan L, Bolton D, McAuliffe O, et al. Bacteriophages in food applications: from foe to friend. Annu Rev Food Sci Technol. 2019;10:151-172.

[49] Wernicki A, Nowaczek A, Urban-Chmiel R. Bacteriophage therapy to combat bacterial infections in poultry. Virol J. 2017;14:1-13.

[50] Węgrzyn G, Kropinski AM, Łoś $M$, et al. Lysogenic conversion in bacteria of importance to the food industry. In: Sabour PM., Griffiths MW, editors. Bacteriophages control food-and waterborne pathog. Washington (DC): American Society of Microbiology; 2010. p. $157-198$.

[51] Erez Z, Steinberger-Levy I, Shamir $M$, et al. Communication between viruses guides lysis-lysogeny decisions. Nature. 2017;541(7638):488-493.

[52] Knowles B, Silveira CB, Bailey BA, et al. Lytic to temperate switching of viral communities. Nature. 2016; 531(7595):466-470.

[53] Nanda AM, Thormann K, Frunzke J. Impact of spontaneous prophage induction on the fitness of bacterial populations and host-microbe interactions. J Bacteriol. 2015;197(3):410-419.

[54] Dydecka A, Bloch S, Rizvi A, et al. Bad phages in good bacteria: role of the mysterious orf63 of $\lambda$ and Shiga toxin-converting $\Phi 24 \mathrm{~B}$ bacteriophages. Front Microbiol. 2017;8:1618.
[55] Mauro SA, Koudelka GB. Shiga toxin: expression, distribution, and its role in the environment. Toxins. 2011;3(6):608-625.

[56] Rehman S, Ali Z, Khan M, et al. The dawn of phage therapy. Rev Med Virol. 2019;29:1-16.

[57] Połaska M, Sokołowska B. Bacteriophages-a new hope or a huge problem in the food industry. AIMS Microbiol. 2019;5(4):324-347.

[58] Tomat D, Migliore L, Aquili V, et al. Phage biocontrol of enteropathogenic and shiga toxin-producing Escherichia coli in meat products. Front Cell Infect Microbiol. 2013;3:10-20.

[59] Tomat D, Mercanti D, Balagué $C$, et al. Phage biocontrol of enteropathogenic and shiga toxin-producing Escherichia coli during milk fermentation. Lett Appl Microbiol. 2013;57(1):3-10.

[60] Le TS, Southgate PC, O'Connor W, et al. Bacteriophages as biological control agents of enteric bacteria contaminating edible oysters. Curr Microbiol. 2018;75(5):611-619.

[61] Ferguson S, Roberts C, Handy E, et al. Lytic bacteriophages reduce Escherichia coli 0157:H7 on fresh cut lettuce introduced through cross-contamination. Bacteriophage. 2013;3(1):e24323.

[62] Liu H, Niu YD, Meng R, et al. Control of Escherichia coli 0157 on beef at 37,22 and $4{ }^{\circ} \mathrm{C}$ by T5-, T1-, T4and 01-like bacteriophages. Food Microbiol. 2015;51: 69-73.

[63] Carter CD, Parks A, Abuladze T, et al. Bacteriophage cocktail significantly reduces Escherichia coli 0157. Bacteriophage. 2012;2(3):178-185.

[64] Sulakvelidze A, Li M, Senecal A, et al. Bacteriophages reduce experimental contamination of hard surfaces, tomato, spinach, broccoli, and ground beef by Escherichia coli 0157:H7. AEM. 2008;74(20): 6230-6238.

[65] Boyacioglu O, Sharma M, Sulakvelidze A, et al. Biocontrol of Escherichia coli 0157:H7 on fresh-cut leafy greens. Bacteriophage. 2013;3(1):e24620.

[66] Dalmasso $M$, Strain $R$, Neve $H$, et al. Three new Escherichia coli phages from the human gut show promising potential for phage therapy. PLoS One. 2016;11(6):e0156773.

[67] Cui H, Bai $M$, Yuan $L$, et al. Sequential effect of phages and cold nitrogen plasma against Escherichia coli 0157:H7 biofilms on different vegetables. Int J Food Microbiol. 2018;268:1-9.

[68] Sadekuzzaman M, Yang S, Mizan MFR, et al. Reduction of Escherichia coli $\mathrm{O} 157: \mathrm{H7}$ in biofilms using bacteriophage BPECO 19. J Food Sci. 2017; 82(6):1433-1442.

[69] Patel J, Sharma M, Millner $P$, et al. Inactivation of Escherichia coli 0157:H7 attached to spinach harvester blade using bacteriophage. Foodborne Pathog Dis. 2011;8(4):541-546.

[70] Lee YD, Park JH. Characterization and application of phages isolated from sewage for reduction of Escherichia coli 0157:H7 IN biofilm. LWT - Food Sci Technol. 2015;60(1):571-577.

[71] Tomat D, Quiberoni A, Mercanti D, et al. Hard surfaces decontamination of enteropathogenic and Shiga 
toxin-producing Escherichia coli using bacteriophages. Food Res Int. 2014;57:123-129.

[72] Snyder AB, Perry JJ, Yousef AE. Developing and optimizing bacteriophage treatment to control enterohemorrhagic Escherichia coli on fresh produce. Int J Food Microbiol. 2016;236:90-97.

[73] Weis M. Impact of the gut microbiome in cardiovascular and autoimmune diseases. Clin Sci. 2018; 132(22):2387-2389.

[74] Hedin CR, van der Gast CJ, Stagg AJ, et al. The gut microbiota of siblings offers insights into microbial pathogenesis of inflammatory bowel disease. Gut Microbes. 2017;8(4):357-359.

[75] Guinane CM, Cotter PD. Role of the gut microbiota in health and chronic gastrointestinal disease: understanding a hidden metabolic organ. Therap Adv Gastroenterol. 2013;6(4):295-308.

[76] Sarker SA, Berger B, Deng Y, et al. Oral application of Escherichia coli bacteriophage: safety tests in healthy and diarrheal children from Bangladesh. Environ Microbiol. 2017;19(1):237-250.

[77] Raya RR, Oot RA, Moore-Maley B, et al. Naturally resident and exogenously applied T4-like and T5-like bacteriophages can reduce Escherichia coli 0157:H7 levels in sheep guts. Bacteriophage. 2011;1(1):15-24.

[78] Cieplak T, Soffer N, Sulakvelidze A, et al. A bacteriophage cocktail targeting Escherichia coli reduces $E$. coli in simulated gut conditions, while preserving a non-targeted representative commensal normal microbiota. Gut Microbes. 2018;9(5):391-399.

[79] De Sordi L, Khanna V, Debarbieux L. The gut microbiota facilitates drifts in the genetic diversity and infectivity of bacterial viruses. Cell Host Microbe. 2017;22(6):801.e3-808.e3.

[80] Cookson AL, Woodward MJ. The role of intimin in the adherence of enterohaemorrhagic Escherichia coli (EHEC) 0157:H7 to HEp-2 tissue culture cells and to bovine gut explant tissues. Int J Med Microbiol. 2003;292(7-8):547-553.

[81] Górski A, Międzybrodzki R, Łobocka $M$, et al. Phage therapy: what have we learned? Viruses. 2018;10(6): 228-288.

[82] Brüssow $\mathrm{H}$. Hurdles for phage therapy to become a reality-an editorial comment. Viruses. 2019;11(6): 557.

[83] Bureau of Chemical Safety of Canada, Food Directorate, Health Products and Food Branch. Antimicrobial food processing aid uses on red meat and poultry meat for which Health Canada has expressed no objection. 2019.

[84] Office of Parliamentary Counsel. Food Standards Australia New Zealand Act 1991, Compilation $n^{\circ} 28$ 2018.

[85] Andreoletti O, Baggesen DL, Bolton D, et al. Scientific opinion on the evaluation of the safety and efficacy of Listex ${ }^{\mathrm{TM}}$ P100 for the removal of listeria monocytogenes surface contamination of raw fish. EFSA J. 2012;10:2615.

[86] Panel E, Hazards B. Evaluation of the safety and efficacy of Listex ${ }^{T M}$ P100 for reduction of pathogens on different ready-to-eat (RTE) food products. EFSA J. 2016;14(8):e04565.
[87] General Secretariat of the Council. Comments on the council's rules of procedure European council's and council's rules of procedure. Luxembourg (Luxembourg): Publications Office of the European Union; 2016.

[88] The Council of the European Union. Council Decision 1999/468/EC laying down the procedures for the exercise of implementing powers (28 June 1999) Consolidated version 2006. Off J Eur Communities. 1999;2:1998-2001.

[89] Andreoletti O, Budka H, Buncic S, et al. The use and mode of action of bacteriophages in food production. Eur Food Saf Auth. 2009;1076:1-26.

[90] Andreoletti O, Baggesen DL, Bolton D, et al. Scientific opinion on the maintenance of the list of QPS biological agents intentionally added to food and feed (2013 update). EFSA J. 2013;11(11):3449.

[91] Fauconnier A. Phage therapy regulation: from night to dawn. Viruses. 2019;11(4):352.

[92] Sundh I, Bolton D, Vlak J, et al. Update of the list of QPS-recommended biological agents intentionally added to food or feed as notified to EFSA 8: suitability of taxonomic units notified to EFSA until March 2018. EFSA J. 2018;16(7):e05315.

[93] Lee $\mathrm{H}, \mathrm{Ku} \mathrm{HJ}$, Lee $\mathrm{DH}$, et al. Characterization and genomic study of the novel bacteriophage HY01 infecting both Escherichia coli 0157:H7 and Shigella flexneri: potential as a biocontrol agent in food. PLoS One. 2016;11(12):e0168985.

[94] Moye Z, Woolston J, Sulakvelidze A. Bacteriophage applications for food production and processing. Viruses. 2018;10(4):205.

[95] Imamovic L, Ballesté E, Martínez-Castillo A, et al. Heterogeneity in phage induction enables the survival of the lysogenic population. Environ Microbiol. 2016;18(3):957-969.

[96] Bonanno L, Delubac B, Michel V, et al. Influence of stress factors related to cheese-making process and to STEC detection procedure on the induction of Stx phages from STEC O26:H11. Front Microbiol. 2017;8: 296-297.

[97] Fang Y, Mercer RG, McMullen LM, et al. Induction of Shiga toxinencoding prophage by abiotic environmental stress in food. Appl Environ Microbiol. 2017; 83:1-13.

[98] Matsushiro A, Sato K, Miyamoto H, et al. Induction of prophages of enterohemorrhagic Escherichia coli O157:H7 with norfloxacin. J Bacteriol. 1999;181(7): 2257-2260.

[99] Liao Y, Quintela IA, Nguyen K, et al. Investigation of prevalence of free Shiga toxin- producing Escherichia coli (STEC) -specific bacteriophages and its correlation with STEC bacterial hosts in a produce-growing area in Saline, California.. Plos One. 2018;13:1-12.

[100] García-Aljaro C, Muniesa M, Blanco JE, et al. Characterization of Shiga toxin-producing Escherichia coli isolated from aquatic environments. FEMS Microbiol Lett. 2005;246(1):55-65.

[101] DebRoy C, Fratamico PM, Yan X, et al. Comparison of O-antigen gene clusters of all O-serogroups of Escherichia coli and proposal for adopting a new nomenclature for O-typing. PLoS One. 2016;11:1-13. 
[102] Looft T, Allen HK, Cantarel BL, et al. Bacteria, phages and pigs: the effects of in-feed antibiotics on the microbiome at different gut locations. ISME J. 2014; 8(8):1566-1576.

[103] Jovel J, Patterson J, Wang W, et al. Characterization of the gut microbiome using $16 \mathrm{~S}$ or shotgun metagenomics. Front Microbiol. 2016;7:1-17.

[104] Chu DM, Antony KM, Ma J, et al. The early infant gut microbiome varies in association with a maternal high-fat diet. Genome Med. 2016;8(1):77.

[105] Seekatz AM, Aas J, Gessert CE, et al. Recovery of the gut microbiome following fecal microbiota transplantation. MBio. 2014;5(3):e00893.

[106] Gasparrini AJ, Crofts TS, Gibson MK, et al. Antibiotic perturbation of the preterm infant gut microbiome and resistome. Gut Microbes. 2016;7(5):443-449.

[107] Doss J, Culbertson K, Hahn D, et al. A review of phage therapy against bacterial pathogens of aquatic and terrestrial organisms. Viruses. 2017;9(3): 50.

[108] Endersen L, O'Mahony J, Hill C, et al. Phage therapy in the food industry. Annu Rev Food Sci Technol. 2014;5:327-349.

[109] Sabouri S, Sepehrizadeh Z, Amirpour-Rostami S, et al. A minireview on the in vitro and in vivo experiments with anti-Escherichia coli 0157:H7 phages as potential biocontrol and phage therapy agents. Int J Food Microbiol. 2017;243:52-57.
[110] Bruttin A, Brüssow H. Human volunteers receiving Escherichia coli phage T4 orally: a safety test of phage therapy. Antimicrob Agents Chemother. 2005; 49(7):2874-2878.

[111] Dudek-Wicher RK, Junka A, Bartoszewicz M. The influence of antibiotics and dietary components on gut microbiota. Prz Gastroenterol. 2018;13(2):85-92.

[112] Sarker SA, Sultana S, Reuteler G, et al. Oral phage therapy of acute bacterial diarrhea with two coliphage preparations: a randomized trial in children from Bangladesh. EBioMedicine. 2016;4:124-137.

[113] Gindin M, Febvre HP, Rao S, et al. Bacteriophage for Gastrointestinal Health (PHAGE) Study: evaluating the safety and tolerability of supplemental bacteriophage consumption. J Am Coll Nutr. 2018:38(1): 68-75.

[114] Maura D, Debarbieux L. On the interactions between virulent bacteriophages and bacteria in the gut. Bacteriophage. 2012;2(4):e23557.

[115] Maura D, Morello E, Du Merle L, et al. Intestinal colonization by enteroaggregative Escherichia coli supports long-term bacteriophage replication in mice. Environ Microbiol. 2012;14(8):1844-1854.

[116] Sarhan W. a, Azzazy HME. Phage approved in food, why not as a therapeutic? Expert Rev anti Infect Ther. 2015;13(1):91-101. 